\title{
Performance Improvement of a Grid Connected Wind Farm System
}

\author{
Dr. Gouranga Chandra Biswal \\ Department of Electrical Engineering Bhilai Institute of Technology, Durg, India
}

\begin{abstract}
Renewable energy sources are becoming more promising means of green energy production. But the increasingly penetration level of wind energy into existing power system presents many technical challenges. Power quality is a measure of the system performance. It requires consideration of problems like voltage regulation, stability, harmonics etc. This paper presents an overview of grid connected system and analysis of its stability. The system is assumed with fixed speed Induction generator integrated to a weak grid. Change and improvement in performance is observed with various FACT devices. The simulation model has been developed in MATLAB/SIMULINK R2016a.
\end{abstract}

Keywords: Wind Farm Integration, Point of Common Coupling, Reactive Power Compensator, Flexible AC Transmission system (FACTS)

\section{Introduction}

With increase in demand of power and decrease of fossil fuels, mankind has been forced to search alternative sources for the generation of electricity. Wind power in spite of being stochastic in nature has proved itself as a viable solution to this problem. As the wind turbine technology is developing at a good pace, more and more wind power plants are being integrated with the conventional form of generation. With the increase in the ratio of wind generation to conventional generation, several problems related with integration of wind farms have emerged. These problems are due to distinct properties of the generators used with the conventional form of generation and wind based generation.

Table 1 below, depicts the world wide data of wind power generation till the end of 2015 .

Table 1: Top ten markets by the end of 2015

\begin{tabular}{|l|l|l|l|}
\hline S. No & Country & MW & \% \\
\hline 1 & China & $1,45,362$ & 34.10 \\
\hline 2 & USA & 75,471 & 17.50 \\
\hline 3 & Germany & 44,947 & 10.50 \\
\hline 4 & India & 27,151 & 06.40 \\
\hline 5 & Spain & 23,025 & 5.40 \\
\hline 6 & U.K & 13,603 & 3.20 \\
\hline 7 & Canada & 11,205 & 2.60 \\
\hline 8 & France & 10,305 & 2.40 \\
\hline 9 & Italy & 8,958 & 2.10 \\
\hline 10 & Brazil & 8,715 & 2.00 \\
\hline & Rest of the World & 58,275 & 13.70 \\
\hline World Total & & $\mathbf{4 , 3 2 , 4 1 9}$ & $\mathbf{1 0 0 . 0 0}$ \\
\hline
\end{tabular}

Source: BTM, Wiser and Bollinger, 2015

In thermal and hydro power based generation, synchronous generators are used while in wind based generation mostly induction generators are used. Induction and synchronous generators do not exhibit similar behavior during power system stresses. Moreover, increase in wind power based generation requires a reliable transmission system for power evacuation to the load centre. As the wind farms are mainly concentrated in far flung and rural areas their interconnection with the grid becomes a problem. This problem is mainly due to the existence weak transmission grids in the rural areas.Wind energy system converts the obtainable kinetic energy in the wind into mechanical energy that can spur an electrical generator. Predominantly, wind power generators are self excited induction generators. Induction generators characteristics are strongly affected by the massive reactive power absorbed during their normal operating conditions. This reactive power trouble may engender dynamic voltage instability in the system. The needed reactive power of induction generator can be provided either by the grid or self capacitor bank in parallel with the generator stator terminals. The stability of a system determines whether the system can settle down to the original or close to the steady state after the transients disappear. Transient stability refers to the capability of a system to maintain synchronous operation in the event of large disturbances such as multi-phase short-circuit faults or switching of lines. The resulting system response 
involves large excursions of generator rotor angles and is influenced by the nonlinear power angle relationship. Stability depends upon both the initial operating conditions of the system and the severity of the disturbance.

Recent development of power electronics introduces the use of flexible ac transmission system (FACTS) controllers in power systems. FACTS controllers are capable of controlling the network condition in a very fast manner and this feature of FACTS can be exploited to improve the voltage stability, and steady state and transient stabilities of a complete power system. Dynamic reactive power compensators are always required to stabilize the voltage and to supply the desired reactive power at wind generator bus under normal and abnormal operation. FACTS devices can be very profitable to simultaneously deliver reactive power and support bus voltage at wind generator interface. The system instability of wind farms based on fixed speed induction generators is largely caused by the excessive reactive power absorption by the fixed speed induction generators after fault due to the large rotor slip gained during fault. The STATCOM considerably improve the system stability during and after disturbances.

\section{FACTS Devices:}

Definition of FACTS from records consistent with IEEE, has the abbreviation of flexible AC Transmission structures, is described as follows:

"Alternating current transmission systems incorporating power electronics based and other static controllers to enhance controllability and power transfer capability"

The solutions to enhance the first-class of deliver of the electrical networks, go through the applications tendencies in semiconductor power systems, this is to mention, the usage of static power converters in electrical networks. The technological advances in electricity semiconductors are permitting the improvement of systems that react greater like a really perfect transfer, completely controllable, admitting high frequencies of commutation to principal levels of tension and energy. Recent development of energy electronics introduces the usage of record controllers in power system.It is well known fact that for reactive power compensation FACTs devices can be used.Table 2. gives an idea about the cost of various reactive power sources including all FACTS devices. The main disadvantage of FACTS devices is expensive. It provides smooth and fast response to secure power system during normal and steady state operations. FACTS controllers may be based on thyristors with no gate turn-off or power devices with gate turn-off capability. FACTS controllers are used for the dynamic control of voltage, impedance and phase angle of high voltage $\mathrm{AC}$ transmission lines.

Table 2. Different FACTS devices as well as their cost

\begin{tabular}{|l|l|l|}
\hline S. No & FACTS Device & Cost (Rs/kVar) \\
\hline 1 & Shunt Capacitor & 432 \\
\hline 2 & Series Capacitor & 1080 \\
\hline 3 & SVC & 2160 (controlled portions) \\
\hline 4 & TCSC & 2160 (controlled portions) \\
\hline 5 & STATCOM & 2700 \\
\hline
\end{tabular}

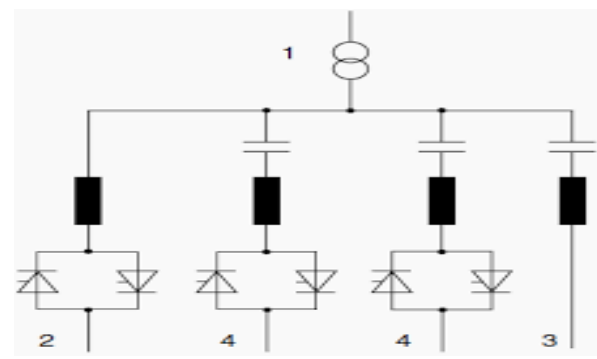

Figure 1. Schematic diagram of a FACT device (SVC)

The thyristor controller and switches provide fast control of the overall SVC reactance between its capacitive and inductive design limits. Due to the network impedance, this capability translates into dynamic bus voltage control. As a consequence, the SVC can improve transmission stability and increase power transmission limits across a given path as shown in figure 1 .

\section{Modelling Of Grid Connected Wind Farm:}

For modeling and simulation of wind farm as mentioned above MATLAB has been used which is shown in fig.1 


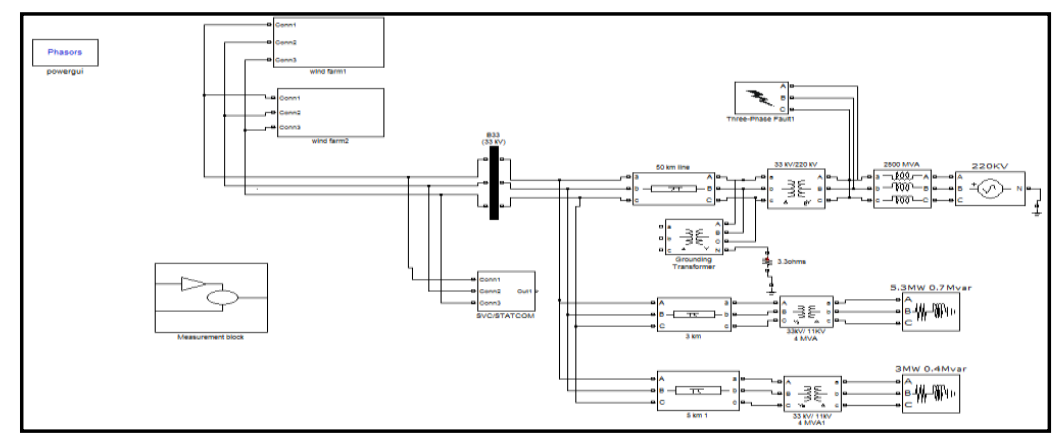

Fig 2: SIMULINK model of a grid connected wind farm.

The figure consist of 2 wind farms each of 12MW capacity, and in each farm three different ratings of wind induction generator is present i.e. $3 \mathrm{MW}, 4 \mathrm{MW}$ and $5 \mathrm{MW}$. The system consists of a $220 \mathrm{KV}, 50-\mathrm{Hz}$, sub transmission system with short circuit level of 2500 MVA, feeds a $33 \mathrm{KV}$ distribution system through 220 $\mathrm{kV} / 33 \mathrm{kV}$ step down transformer. A 20MVA FACTS device is used as reactive power compensator at the common point of coupling.

\section{Results And Discussions}

The dynamic behaviors of the wind farm distribution network with and without the application of an external three-phase fault with and without reactive power compensation are investigated for 'the constant wind speed'. The dynamic performance of WTIG for the constant wind speed is analyzed for different cases:

1) Case 1: without Fault and without STATCOM

2) Case 2: without fault and with STATCOM

3) Case 3: with fault and without STATCOM

4) Case 4: with fault and with STATCOM

A consistent wind velocity of $11 \mathrm{~m} / \mathrm{s}$ is applied to the wind turbine.

The reaction of the lively electricity injected into the network is low in the casel because no reactive energy assist in the community, because of insufficient reactive power reimbursement WTIG machine stability is lost.The active electricity is injected to the distribution network reduces considerably for the cases 3 when a 3 phase fault is applied at $\mathrm{t}=3 \mathrm{sec}$. and cleared $3.1 \mathrm{sec}$. For the case of machine without STATCOM, the active strength injected will become very low with and without fault. However, for the cases $2 \& 4$ of system with STATCOM, due to the reactive electricity support, the stability of the machine is maintained and the WTIGs keep delivering the approximate rated electricity to the distribution network after the fault clearance.The reaction of the WTIG speed will increase, for the case 1 and while a three segment fault is carried out at $t=3 \mathrm{sec}$. And cleared 3.1sec.For case3 of device without STATCOM, the system looses balance and the velocity of the WTIG maintains to growth. For the machine with STATCOM (case2\&4), the steadiness of the system is maintained after the fault clearance. This is due to the fact that, the reactive power supplied through the STATCOM.The reaction of the WTIG terminal voltage drops drastically for the cases 1 and the low voltage condition starts at $\mathrm{t}=3 \mathrm{sec}$, at which the fault is implemented and lasts for $3.1 \mathrm{sec}$.For case of system without STATCOM, the WTIG terminal voltage drops straight away after the fault clearance. For the device with STATCOM due to reactive energy help, the WTIG terminal voltage is slightly accelerated at once after the fault clearance. So the system maintains stability and finally the WTIG terminal voltage recovers for both the cases $2 \& 4$.The results are shown in fig2 to 5 .
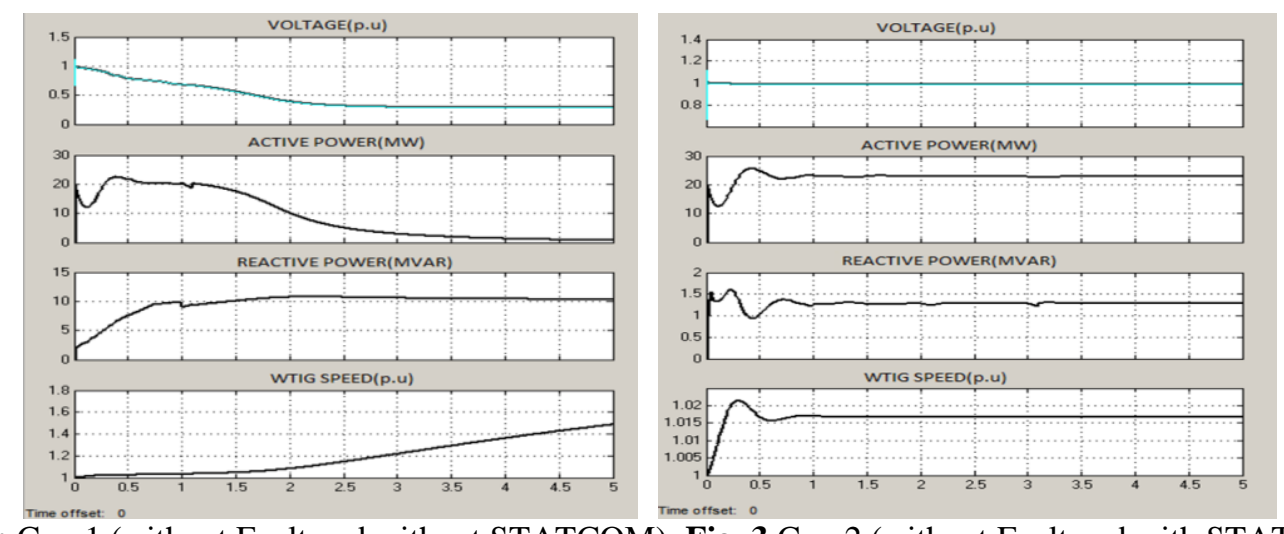

Fig. 3: Case1 (without Fault and without STATCOM) Fig. 3 Case2 (without Fault and with STATCOM) 
As from figure 2 and 3 it can be inferred that voltage quality as well as stability of the system is increased by a good margin. Thus, STATCOM turns out to be a good compensator; also the voltage is maintained at a nominal value. Similarly, the other two cases are also shown in figure 4 and 5 .
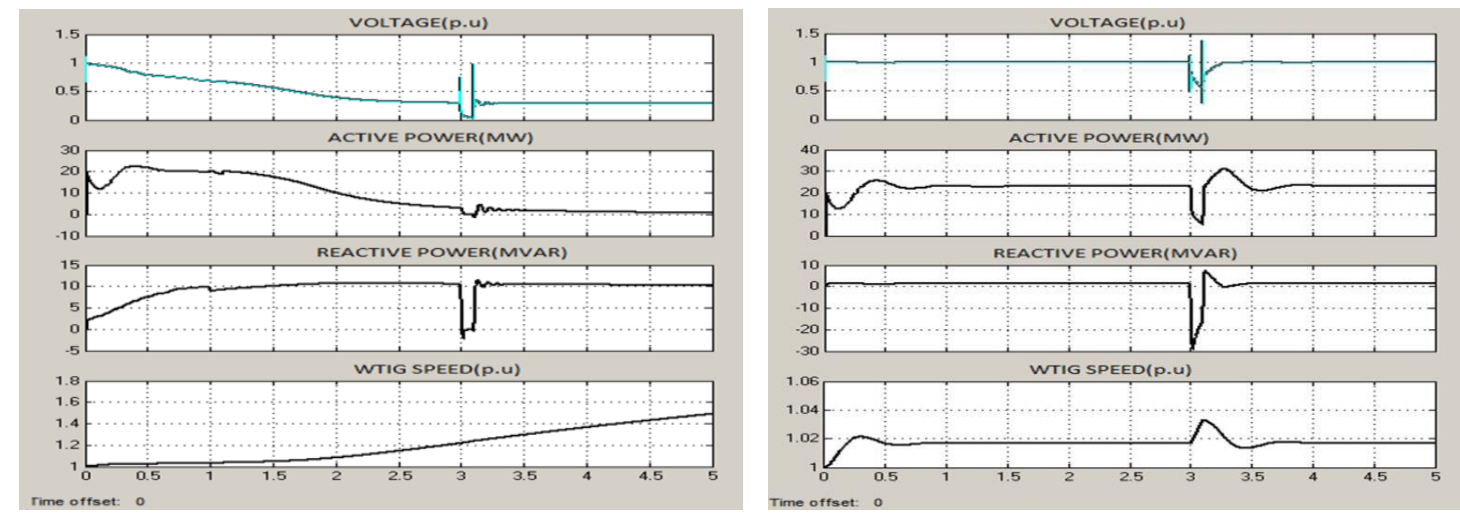

Fig. 4: Case3 (with Fault and without STATCOM)

Fig. 5: Case 4 (with Fault and with STATCOM)

From figure 4 and figure 5 depicting the two cases with faults, the overall system turns out to be stable as STATCOM helps to regain the nominal voltage back to normal state by providing additional reactive and active power.

\section{Conclusion}

This paper investigates the effect of STATCOM in a wind energy connected distribution network. The stability improvement of a distribution system connected with WTIG is studied. The dynamic behaviors of the wind farm distribution system with and without the application of an external three-phase fault with and without STATCOM are investigated. The amount of active power supplied to the grid is more and reactive power supplied by grid is low for the cases with STATCOM than for the cases without STATCOM. It is also found that the WTIG with no STATCOM has lower value of rotor speed and has higher value on terminal voltage than with STATCOM.

\section{References}

[1] Sharad W. Mohod and Mohan V. Aware,"A STATCOM-Control Scheme for Grid Connected Wind Energy System for Power Quality Improvement” IEEE SYSTEMS JOURNAL, VOL. 4, NO. 3, SEPTEMBER 2010.

[2] Yogesh Kumar, Jordan Ringenberg, Soma Shekara Depuru, Vijay K. Devabhaktuni, Jin Woo Lee, Efstratios Nikolaidis, Brett Andersen, Abdollah Afjeh,"Wind energy: Trends and enabling technologies", Renewable and Sustainable Energy Reviews 53 (2016) 209-224

[3] Rajiv Singh, Asheesh Kumar Singh, and Ashutosh Kumar Singh "Transient Stability Improvement of a FSIG Based Grid Connected wind Farm with the help of a SVC and a STATCOM: A Comparison". International Journal of Computer and Electrical Engineering, Feb 2012. Vol.4, No.1,

[4] Qusay.Salem “Overall Control Strategy of Grid Connected to Wind Farm Using FACTS" Bonfring International Journal of Power Systems and Integrated Circuits, , Feb 2014,Vol. 4, No.1.

[5] S.N. Deepa1, J. Rizwana, S.N. Deepa et.al“Multi-Machine Stability of a Wind Farm Embedded Power System using FACTS Controllers" Anna University Regional Centre, Coimbatore, Tamilnadu India International Journal of Engineering and Technology (IJET) ISSN : 0975-4024 Oct-Nov 2013.Vol 5 No 5.

[6] Sidhartha Panda and N.P.Padhy, "Investigating the Impact of Wind Speed on Active and Reactive Power Penetration to the Distribution Network" International Journal of Electrical and Electronics Engineering 1:1 2008

[7] B. T. Ramakrishna Rao, P. Chanti, N. Lavanya, S. chandra Sekhar, Y. Mohan kumar " Power System Stability Enhancement Using Fact Devices" Int. Journal of Engineering Research and Applications ISSN : 2248-9622, April 2014, Vol. 4, Issue 4( Version 1), pp.339-344

[8] N.Kamaraj S.Vijayarajan,G. Lakshmi Thilagam "Reactive Power Control of A Grid Connected Wind Turbine Induction Generator"IEEE transactions

[9] N. G. Hingorani and L. Gyugyi, Understanding FACTS: Concepts and Technology of Flexible AC Transmission System. IEEE Press. 2000.

[10] Shukla S.P. et all,Wind power:issues related with microgrid" Dipesh K. Sharma, S.P. Shukla. Wind Power: Issues Related with Microgrid. Research J. Engineering and Tech. 6(2):April-June,2015page 250-257.

[11] Biswal G.C.,Shukla S.P. “ Development Trends in wind energy conversion system : A review”, IJRITCC, ISSN-2321-8169,July 2015,pp 4885-4888. 